to customers infringe the consumer protection regulations, and it is likely to involve the coal merchants in financial loss. It pays everyone to keep coal dust to a minimum.

Whether any depot is a nuisance in law must be decided - on the local circumstances and evidence, but that the problem is not a simple one is clear from Irvine and Davies's paper. So long as raw coal is used for domestic and industrial purposes, so long will concentration of depots be an economic necessity. Reasonable siting, careful management, and screening so far as practicable from the gaze of the neighbours will minimize the annoyance they are apt to cause. "What the eye doesn't see the heart doesn't grieve over" is not a sound maxim in regard to noxious agents, but where subjective and psychological factors are involved "Out of sight, out of mind" is not an unwholesome tag to apply.

\section{Transport of Specimens to the Laboratory}

Ever since the inception of the Public Health Laboratory Service in 1939 public health laboratories, of which there are now 62 throughout England and Wales, have accepted specimens from general practitioners for microbiological investigation. More recently it has become the declared policy of the Department of Health and Social Security that general practitioners shall have open access to the facilities of all N.H.S. hospital diagnostic laboratories. So far so good. But there is still a serious problem. How can the doctor get the specimen to the laboratory ? If the patient is well enough, he or she can take it. If not, a relative or even the doctor himself may provide the necessary transport. In some areas the medical officer of health has arranged that specimens left at local authority clinics or other suitable collecting centres will be transported to the appropriate hospital or public health laboratory. This would seem to be a sensible arrangement which might be developed with advantage throughout the country.

Even with the best of delivery services for specimens, delay of several hours is likely. For some specimens the delay may not significantly affect results, but for most microbiological specimens it may be disastrous. Though swabs can be sent in a suitable transport medium, usually obtainable from the laboratory, specimens of urine present a special problem. Since the work of E. H. Kass ${ }^{1}$ it has become generally accepted that the presence of more than 100,000 organisms per $\mathrm{ml}$. in a properly collected and freshly passed specimen of urine is indicative of urinary infection. Urine itself is a good culture medium in which bacteria may multiply rapidly during the time between the passing of the specimen by the patient and its arrival in the laboratory. The numbers of organisms present when the specimen reaches the laboratory may therefore greatly exceed the number present when the urine was passed by the patient. There is a serious risk that contaminating organisms of no significance may multiply and be present in apparently significant numbers by the time the specimen is examined in the laboratory. Refrigerating the specimen during transit is one way of overcoming this, but is clearly not ideal.

1 Kass, E. H., Transactions of the Association of American Physicians, 1956. 69, 56.
A paper by Drs. I. A. Porter and J. Brodie at page 353 of the B.M.f. this week describes the use of boric acid in a final concentration of $1.8 \%$ as a preservative for urine specimens. Compared with dip-inoculum transport medium and also an ice-box, boric acid in their hands gave as good results and provided a simpler and almost certainly cheaper means of transporting the urine. Apart from the effect of boric acid on maintaining bacteria in the samples in a state of virtually suspended animation, it was shown not to have any adverse effect on the content of albumin and sugar. Furthermore, the numbers of red and white blood cells and casts did nor appreciably diminish. The authors point out that one possibl: hazard of the boric acid outfit is that the powder may be emptied out before the addition of urine, despite instructions to the contrary on the label. It should not be beyond the wit of man to devise a means of causing the boric acid to adhere to the inside of the container. Certainly the use of boric acid for the preservation of urine in the manner described should be tried by others. It might well provide a simple solution to an important problem.

\section{Scotland Goes Forward}

While doctors in England and Wales are still waiting for Mr. Crossman to produce his revised version of the Green Paper $^{1}$ on the administration of the N.H.S. their colleagues in Scotland have accepted the principle of unification. It seems likely that they will soon reach broad agreement with the Scottish Home and Health Department on the future pattern of their health services.

The special meeting of representatives held in Edinburgh on 24 April (see Supplement, p. 79) rejected any phased or partial unification of the N.H.S., and recommended that area health boards should provide the full range of services, including preventive medicine and the planning and development of health centres and hospitals. Nevertheless, both general practitioners and hospital staff are still apprehensive that an area board might be too remote for day-to-day management in comparison with the present executive councils and hospital boards of management. In England a second tier, as proposed by $\mathrm{Mr}$. Crossman at Norwich, ${ }^{2}$ may be the solution. In Scotland, on the other hand, a single tier system of more and smaller boards might prove satisfactory, with some specialized services organized on a national basis. This is one of the problems still to be discussed.

The Scottish Green Paper ${ }^{3}$ had already indicated that local authorities would be kept distinct from area health boards, so the meeting reserved judgement on the possible advantages or disadvantages of boards having the same boundaries as the future new local authorities. The Scottish G.M.S. Committee has approved the principles of integration and of area boards, though it has suggested that 17-21 boards would be a better number than the $10-15$ proposed in the Green Paper. The meeting also agreed that if management of the Health Service is to be efficient, then arrangements for reimbursement of expenses should be generous enough to attract the "best

\footnotetext{
The Administrative Structure of the Medical and Related Services in England and Wales. London, H.M.S.O., 1968.

2 British Medical fournal, 1969, 1, 590.

s Administrative Reorganization of the Scottish Health Services. Edinburgh, H.M.S.O., 1968.
} 